\title{
QUALIDADE SENSORIAL DE MAÇÃS PRODUZIDAS EM DIFERENTES SISTEMAS DE PRODUÇÃO
}

\section{SENSORIAL QUALITY OF APPLES IN DIFFERENT SYSTEMS PRODUCTION}

\author{
Carlos Roberto MARTINS ${ }^{1}$ \\ João Carvalho FARIA ${ }^{2}$ \\ Cesar Valmor ROMBALDI ${ }^{2}$ \\ Roseli de Mello FARIAS ${ }^{3}$
}

\section{RESUMO}

O objetivo deste trabalho foi determinar os efeitos dos sistemas de produção nos atributos de qualidade sensorial, na colheita e após a conservação pós-colheita, de maçãs produzidas em pomares conduzidos em sistemas de produção convencional, em transição convencional-orgânico, integrado e orgânico. Foram colhidas maçãs cvs. Imperial Gala, Fuji Suprema e Catarina, em pomares comerciais no município de São Joaquim/SC na safra de 2002/03, nestes quatro sistemas de produção. As frutas foram armazenadas em atmosfera convencional à $0 \pm 1^{\circ} \mathrm{C}$ e $93 \pm 5 \%$ de UR, por 3 meses para a 'Imperial Gala', e 5 meses para a 'Fuji Suprema' e 'Catarina', seguidos de 7 dias à $15-20^{\circ} \mathrm{C}$. As avaliações sensoriais foram realizadas na colheita e após armazenamento. Na avaliação conjunta das maçãs nos sistemas de produção pode-se verificar, de modo geral, uma superioridade nas características visuais das frutas produzidas em pomares conduzidos nos sistemas de produção integrado e orgânico. Na característica degustativa, de modo geral, verificou-se superioridade nas frutas produzidas em sistema integrado e orgânico, ressaltados pelos atributos de acidez, sabor, suculência e maciez. As frutas produzidas no sistema integrado e orgânico apresentam qualidade sensorial superior às frutas produzidas nos demais sistemas de produção.

Palavras-chave: Malus domestica; produção orgânica; produção integrada.

\begin{abstract}
The objective was to evaluate the quality sensory of post-harvest apples grown under conventional production systems in transition from conventional-organic, organic and integrated. Apples Imperial Gala, Fuji Suprema and Catarina were harvested in commercial orchards in the municipality of São Joaquim / SC in the 2002/03 seasons in four production systems. The fruit were stored under conventional atmosphere $0 \pm 1{ }^{\circ} \mathrm{C}$ and $93 \pm 5 \% \mathrm{RH}$ for 3 months for the 'Imperial Gala' and 5 months for the 'Fuji Suprema' and 'Catarina', followed by 7 days at $15-20{ }^{\circ} \mathrm{C}$. The sensory evaluations were performed at harvest and after of storage. In the joint evaluation of the apples in production systems may arise in a superior visual characteristics of fruit grown in orchards conducted in integrated production systems and organic. In characteristic taste it is superior in fruit grown in organic and integrated system, emphasizing the attributes of acidity, flavor, juiciness and tenderness. The fruits produced in organic and integrated system exhibit superior sensory quality those produced in other production systems.
\end{abstract}

Key-words: Malus domestica; organic production; integrated production.

\footnotetext{
${ }^{1}$ Engenheiro Agrônomo, Dr., Professor da Faculdade de Zootecnia, Veterinária e Agronomia da Pontifícia Universidade do Rio Grande do Sul (PUCRS), Rua Monte Casseros, n³109, CEP 97510380, Uruguaiana, Rio Grande do Sul, Brasil. E-mail carlos.martins@pucrs.br Autor para correspondência

2 Engenheiro Agrônomo, Dr., Professor Faculdade de Agronomia Eliseu Maciel (FAEM) / Universidade Federal de Pelotas (UFPel), CP 354 96010-900, Pelotas,Rio Grande do Sul, Brasil. E-mail: jfaria@ufpel.edu.br; cesar.rombaldi@pq.cnpq.br

${ }^{3}$ Engenheira Agrônoma, M.Sc. Professora da Universidade Estadual do Rio Grande do Sul (UERGS), Alegrete, Rio Grande do Sul, Brasil. Email: roseli-farias@uergs.edu.br
} 
MARTINS , C.R. et al. Qualidade sensorial de maçãs...

\section{INTRODUCÃO}

Nas últimas décadas aumentou a procura por alimentos produzidos de forma orgânica, principalmente pelo menor risco da ocorrência de doenças associadas ao consumo de alimentos contendo aditivos, resíduos de agroquímicos, hormônios e toxinas (Azevedo, 2003). Soma-se a isto, a evolução da consciência ecológica que evidencia a necessidade do setor agropecuário ter seus processos comprometidos com a sustentabilidade do agroecossistema. A produção de frutas mais saudáveis e com menor impacto ambiental é o objetivo dos sistemas de produção integrada e também do orgânico.

De acordo com alguns autores (Cerveira \& Castro, 2000; Souza, 2003), existe uma formação de conceito entre os consumidores, influenciados por estratégias de marketing, que alimentos produzidos organicamente são mais nutritivos, mais saborosos e desempenham suas funções alimentares de forma mais eficaz, comparados com os alimentos produzidos convencionalmente. Acima das questões sociais e ambientais, a produção orgânica de frutas tem gerado controvérsias quanto a sua superioridade sensorial (Hutchins \& Greenhalgh, 1997). Assim, por exemplo, alguns autores (Darolt, 2001; Azevedo, 2003) citam que, além de serem livres de resíduos de agroquímicos, os alimentos produzidos organicamente possuem maior longevidade pós-colheita e melhores características sensoriais, por conterem mais açúcares e ácidos orgânicos; melhor valor nutricional e maior teor de matéria seca e, por conseqüência, terão menos água livre no alimento, condicionando a menor proliferação de microorganismos fitopatogênicos que podem deteriorar as frutas. Como as pesquisas nesta área são poucas, a unanimidade está longe de ser alcançada.

Conjuntos de atributos ou propriedades estão associados à qualidade pós-colheita das frutas, que faz com que se tornem mais apreciáveis como alimentos. De modo abrangente, a qualidade pode ser definida como o conjunto de características que diferenciam componentes individuais de um mesmo produto, e que tem influência na determinação do grau de aceitação do consumidor (Suslow, 2002). De acordo com Lampkin (1990), a qualidade dos alimentos não pode ser definida, exclusivamente, tendo por base uma característica individual mensurável. Dessa forma, devem ser considerados os atributos físicos e sensoriais, bem como devem ser realizadas associações ou relações entre medidas objetivas e subjetivas, para um melhor entendimento das transformações que ocorrem, e que afetam ou não a qualidade das maçãs. As características físicas como massa, tamanho e coloração influenciam a aceitabilidade da fruta pelo consumidor, ao passo que as características intrínsecas, como doçura e acidez, entre outros, perfazem as características organolépticas (sensoriais), importantes tanto na industrialização quanto no consumo das frutas in natura (Czelusniak et al., 2003).

A qualidade pós-colheita das frutas depende crucialmente de ações tomadas ainda quando as frutas estão no pomar. Entre essas se destacam, o local de produção, a poda, o raleio, o manejo do solo, a irrigação, o controle de pragas e doenças, o estádio de maturação e os cuidados na colheita, além das características peculiares de cada sistema de produção (Fergunson et al., 1999). Vale ressaltar que os sistemas de produção de maçãs caracterizam-se como convencionais quando incorporam no seu processo produtivo, práticas e técnicas consideradas padronizadas no qual a intensificação do sistema produtivo, ocorre com base na "Agricultura Moderna", na utilização de insumos externos à propriedade, na utilização de forma desordenada de fertilizantes solúveis e agrotóxicos (Altieri \& Rosset, 1995). Para Silva (1999), o sistema de produção em transição é o termo usualmente utilizado para denominar o processo de mudança do sistema convencional para o sistema de produção orgânico, que segue o processo de normatização estabelecido na Instrução Normativa 07/99 do Ministério de Agricultura e do Abastecimento, publicada pelo Diário Oficial da União em 17 de maio de 1999 (BRASIL, 1999). Esta mesma normativa estabelece os parâmetros para o enquadramento do sistema de produção orgânico. No sistema de produção integrada conforme as normas técnicas gerais para a produção integrada de frutas - NTGPIF e as normas técnicas especificas para a produção integrada de maçãs - NTEPIM de acordo com a Instrução Normativa $\mathrm{N}^{0} 20$, de 27 de setembro de 2001.

Embora a qualidade das maçãs não possa ser melhorada, mas somente mantida após a colheita, poucas pesquisas têm sido conduzidas para verificar a influência dos sistemas de produção na qualidade sensorial e potencial de conservação de maçãs. Neste contexto o objetivo deste trabalho foi determinar os efeitos dos sistemas de produção nos atributos de qualidade sensorial na colheita e após a conservação pós-colheita de maçãs produzidas em pomares conduzidos em sistemas de produção convencional, em transição convencional-orgânico, integrado e orgânico.

\section{MATERIAL E MÉTODOS}

As frutas foram colhidas em pomares comerciais do município de São Joaquim, Estado de Santa Catarina, na safra de 2002/2003. Foram selecionados três pomares de macieiras todos localizados na região da Chapada Seca. As cultivares estudadas foram Imperial Gala, Fuji Suprema, e Catarina, em pomares formados com mudas sobre o porta-enxerto Marubakaido. Com exceção da cv. Catarina no sistema convencional, todas as demais cultivares e sistemas de produção foram avaliados. Os pomares foram conduzidos nos 
MARTINS , C.R. et al. Qualidade sensorial de maçãs...

sistemas de produção integrada (PI), convencional (PC), em transição do convencional para o orgânico (PET) e orgânico (PO). À distância entre os pomares é aproximadamente de $1 \mathrm{~km}$ do pomar do sistema integrado para os sistemas em transição e convencional e de aproximadamente $3 \mathrm{~km}$ para o sistema orgânico. O clima do município de São Joaquim bem como a localidade da Chapada Seca, onde se encontram os pomares em estudos, pertence à variedade específica Cfb da classificação climática de Köppen, ou seja, temperado mesotérmico úmido e verão ameno, caracterizado, por apresentar temperatura média anual de $13,5{ }^{\circ} \mathrm{C}$, máxima média anual $19{ }^{\circ} \mathrm{C}$, mínima média anual de $9,2{ }^{\circ} \mathrm{C}$, precipitação média anual de $1.500 \mathrm{~mm}$ e umidade relativa do ar (média) $81 \%$, sendo os meses mais quentes janeiro e fevereiro, os mais frios junho e julho, mais chuvosos agosto e setembro e mais secos dezembro e janeiro, conforme dados da estação meteorológica localizada na estação da Epagri (EPAGRI, 1999). As geadas são freqüentes com uma ocorrência anual aproximada de 20 a 36 geadas, sendo que o número de horas de frio anual, abaixo de $7,2^{\circ} \mathrm{C}$; é em torno de $800 \mathrm{~h}$ e abaixo de $13{ }^{\circ} \mathrm{C}$ de aproximadamente $2.900 \mathrm{~h}$. A insolação em horas anuais é acima de 1850 h (EPAGRI, 1999). Dados meteorológicos obtidos na estação de avisos fitossanitários/Cidasc junto à Estação Experimental de São Joaquim/Epagri localizada cerca de $10 \mathrm{~km}$ dos pomares em estudo, juntamente com o acompanhamento local, evidenciam que todos estiveram sobre a mesma influência climática, não havendo nenhuma intempérie que pudesse interferir diretamente nos pomares.

As frutas foram colhidas aleatoriamente no pomar, priorizando aquelas frutas no estádio de maturação fisiológico ideal para o armazenamento (coloração de fundo verde amarelado). Imediatamente após colheita, as frutas foram selecionadas, eliminando-se aquelas com defeitos e padronizadas quanto ao estádio de maturação conforme Girardi et al. (2002). As frutas de cada pomar foram armazenadas em câmara refrigerada experimental da Embrapa Uva e Vinho, com temperatura de $0 \pm 1{ }^{\circ} \mathrm{C}$ e $93 \pm 5 \%$ de umidade relativa (UR).

Para o acompanhamento da conservação e qualidade das maçãs, foram utilizadas três repetições por tratamento, sendo cada uma composta por 20 frutas. As avaliações foram realizadas na instalação do experimento (colheita = 0 dias), aos três meses de armazenagem para cvs. Imperial Gala, e aos cinco meses para cvs. Fuji Suprema e Catarina, mais sete dias após a retirada das frutas da câmara fria. Neste caso, as frutas foram mantidas em ambiente de simulação de comercialização de $20 \pm 3{ }^{\circ} \mathrm{C}$ e $75 \% \pm 5 \%$ (UR). As análises foram realizadas nos laboratórios de póscolheita da Embrapa Uva e Vinho. A metodologia empregada para análise sensorial foi realizada com auxílio de uma equipe de 15 julgadores, previamente treinados, pertencentes ao quadro técnico da Embrapa Uva e Vinho. Os testes foram conduzidos no Laboratório de Análise Sensorial com cabines individuais, livres de adores e ruídos estranhos, conforme as normas da ABNT (1993). Inicialmente as amostras contendo 10 frutas foram expostas em bandejas e codificadas com três dígitos para avaliação dos aspectos externos. Para avaliação dos aspectos internos as amostras foram servidas aleatoriamente aos julgadores em copos plásticos, com quantidades padronizadas (aproximadamente $5 \mathrm{~g}-5$ fatias) também previamente codificadas. Foi fornecida água para limpeza do palato entre a avaliação das amostras.

Os atributos avaliados contemplaram características externas e internas. Para avaliações dos aspectos externos foram consideradas a desidratação, a aparência e a coloração. Para aspectos internos das frutas avaliou-se a acidez, o sabor, o aroma e, ainda foram avaliadas a qualidade e aceitação comercial. A avaliação foi realizada por métodos descritivos, teste de avaliação de atributos, usando escalas não estruturadas de $9 \mathrm{~cm}$, cujo extremo esquerdo representou a menor nota, e o direito, a maior intensidade das características analisadas (Figura $1)$.

Para cada safra e cultivar o delineamento experimental foi inteiramente casualizado, com 3 repetições de 20 frutas por cultivar e sistema de produção. Os resultados foram avaliados utilizandose modelos de análise de variância e comparação de médias pelo teste Tukey, ao nível de $5 \%$ de probabilidade de erro.

\section{RESULTADOS E DISCUSSÃO}

A coloração das maçãs é um dos atributos de qualidade mais atrativo para o consumidor. Embora a coloração das frutas, na maioria dos casos, não contribua para o aumento efetivo do valor nutritivo ou da qualidade comestível da fruta, as maçãs de coloração avermelhada, preferentemente as avermelhadas rajadas sobre o fundo verde amarelada, são as mais aceitas pelos consumidores brasileiros (Camilo \& Denardi, 2002).

As melhores pontuações no que concerne à coloração das maçãs, 'Imperial Gala', foram obtidas naquelas provenientes de pomares conduzidos nos sistemas integrado e orgânico, tanto na colheita quanto após o armazenamento (Tabela 1).

Os valores desta avaliação caracterizaram essas frutas de coloração "boa a ótima". $\mathrm{Na}$ colheita as maçãs 'Fuji Suprema' provenientes de pomar conduzido em sistema integrado e orgânico receberam as melhores notas de coloração (boa a ótima), sendo significativamente superiores às frutas produzidas em pomar conduzido em sistema convencional e em transição.

Entretanto, na avaliação após o armazenamento, não foram constatadas diferenças nas características de coloração das frutas provenientes de pomares conduzidos nos sistemas orgânico, integrado e em transição. As frutas destes sistemas foram significativamente superiores, em coloração, às maçãs cv. Fuji Suprema provenientes 
MARTINS , C.R. et al. Qualidade sensorial de maçãs...

de pomar conduzido em sistema convencional (Tabela 1). Na cv. Catarina não foi constatada diferença na coloração das frutas, no momento da colheita, entre os sistemas de produção. Porém, após o armazenamento as frutas produzidas em sistema integrado apresentaram melhores características do que as dos demais sistemas.

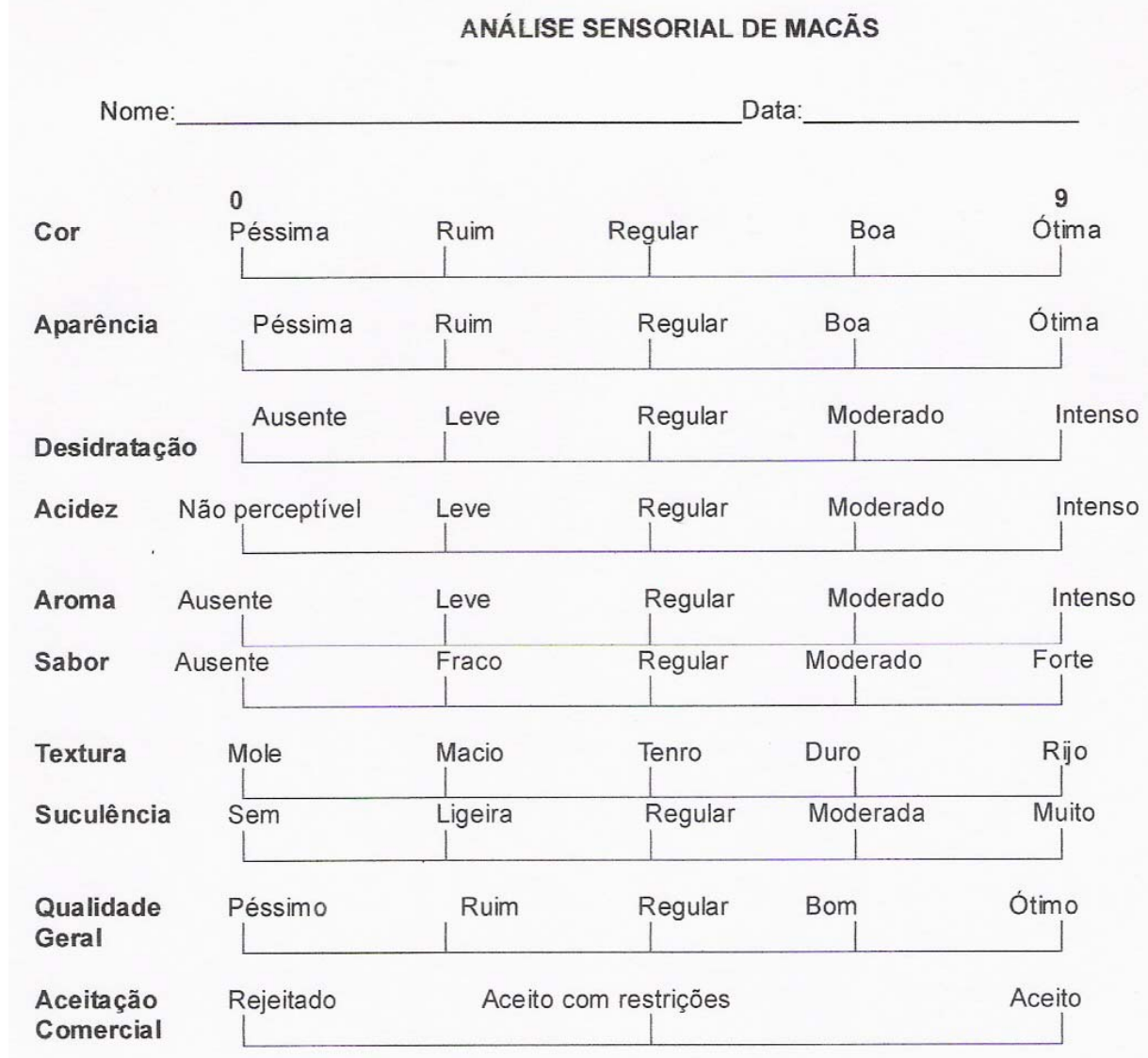

FIGURA 1 - Modelo de ficha empregada na avaliação sensorial hedônica (9 pontos) descritiva quantitativa.

Ribeiro et al. (2002) relataram que maçãs cv. Royal Gala produzidas em sistema orgânico apresentaram maior porcentagem de cor vermelha na casca do que as produzidas em sistema convencional. Segundo estes autores a maior intensidade de cor vermelha nas frutas cultivar neste sistema é atribuída ao menor vigor vegetativo das plantas, menor enfolhamento e maior penetração de radiação solar no interior da copa das plantas, aliados ao atraso de maturação que permite um maior período de incidência de luz sobre as frutas.

Em relação à desidratação das frutas não foram detectadas diferenças entre os sistemas para nas cvs. Catarina e Fuji Suprema. Na cv. Imperial Gala foi observada maior nas frutas produzidas em sistemas de transição do que na produção integrada e orgânica (Tabela 1). Porém, em todas as avaliações os índices apontados pelos julgadores permaneceram na faixa de "praticamente ausentes" para "leve desidratação".

A aparência das maçãs é fator fundamental na determinação do valor de comercialização, sendo representado pela uniformidade das características típicas de cada cultivar, avaliados por diferentes atributos, tais como tamanho, forma, coloração e presença de defeitos. No que concerne à aparência geral, houve efeito significativo do sistema de produção. De maneira geral as frutas produzidas nos sistemas integrado e orgânico apresentaram qualificação superior, ou seja, aparência na faixa de "boa a ótima" (Tabela 1). As maçãs 'Imperial Gala' produzidas em sistemas de transição apresentaram-se, tanto na colheita quanto após o armazenamento, inferiores no quesito aparência, sendo caracterizadas pelos julgadores na faixa de "ruim a regular". Já para a cv. Fuji Suprema, em ambos os períodos avaliados, os menores valores correspondentes à aparência foram obtidos naquelas frutas provenientes de sistema em transição e convencional, também caracterizadas na faixa de "ruim a regular". $\mathrm{Na}$ cv. Catarina, no momento da colheita, as melhores notas de aparência, representados na faixa de "regular a boa", foram atribuído às frutas produzidas em sistema orgânico, que foram superiores ao 
MARTINS , C.R. et al. Qualidade sensorial de maçãs...

sistema de transição. Mas, após o armazenamento, as melhores avaliações de aparência foram atribuídas somente às frutas do sistema integrado, na faixa de "boa a ótima", enquanto que as maçãs dos sistemas orgânico e em transição apresentaram semelhante qualificação, na faixa de "ruim a regular".

Observou-se, de modo geral, que as maçãs produzidas em pomares conduzidos em sistemas integrado e orgânico apresentaram características visuais semelhantes, tanto na colheita como após o armazenamento, conferindo melhor qualidade visual a essas frutas, frente àquelas provenientes de pomares conduzidos nos sistemas em transição e convencional.

Com relação à questão visual dos produtos agrícolas orgânicos, pode-se observar que os efeitos descritos, relativos a este sistema de produção, são variados e dependentes de muitos fatores. Segundo Azevedo (2003), produtos como hortaliças e frutas obtidas em sistema orgânico apresentam coloração mais intensa do que os produzidos convencionalmente. De acordo com Darolt (2001), a aparência visual de maçãs cv. Golden Delicious produzidas em pomar orgânico foi semelhante à das produzidas sob sistema convencional. $\mathrm{Na}$ literatura, outras opiniões divergentes são encontradas. Hutchins \& Greenhalgh (1997) e Ormond et al. (2002) citam que há dificuldade em se avaliar a qualidade visual em função dos sistemas de cultivo. A diversidade de fatores envolvidos e a dificuldade de isolar, ou mesmo identificar, torna difícil verificar a interferência de fatores isolados.

Outra questão relevante na preferência de frutas orgânicas é que os consumidores reduzem as suas exigências quanto à qualidade visual, quando se conscientizam da existência nas frutas, de outros atributos de maior importância, como por exemplo, a inexistência de resíduos de agrotóxicos e de fertilizantes solúveis nos alimentos (Borguini, 2003; Azevedo, 2003). Segundo Cerveira \& Castro (2000) a opinião pública foi alertada mundialmente para os malefícios dos resíduos de agroquímicos, o que passou a ser fator determinante no aumento de consumo de produtos orgânicos.

A maturação das frutas, em geral, conduz a um aumento na doçura, devido à elevação do teor de açúcares, decréscimo da acidez e da adstringência e aumento das características aromáticas, pela emanação dos compostos voláteis (Chitarra, 1994). As diferenças nas características degustativas das frutas são em virtude da espécie, cultivar, estando não só relacionadas com algumas substâncias específicas predominantes, mas também com o local, as condições de clima e o sistema de cultivo em que são produzidas (Saftner et al., 2002).

TABELA 1 - Notas de coloração, desidratação e aparência de maçãs, cvs. Imperial Gala, Fuji Suprema e Catarina produzidas em pomares conduzidos em sistemas convencional (PC), integrado (PI), em transição convencional-orgânico (PET) e orgânicos (PO) na colheita e após armazenamento em atmosfera convencional, safra 2002/2003. São Joaquim, SC, 2004

\begin{tabular}{|c|c|c|c|c|c|c|c|}
\hline \multirow{2}{*}{ Características } & \multirow{2}{*}{ Períodos } & \multirow{2}{*}{ Cultivares } & \multicolumn{4}{|c|}{ Sistema de produção } & \multirow[b]{2}{*}{ DMS } \\
\hline & & & $\mathrm{PC}$ & $\mathrm{PI}$ & $\mathrm{PET}$ & $\mathrm{PO}$ & \\
\hline \multirow{6}{*}{ Coloração } & \multirow{3}{*}{ Na Colheita } & I. Gala & $7,1 \mathrm{~b}$ & $8,9 a$ & $4,2 c$ & $8,9 a$ & 1,27 \\
\hline & & Fuji S & $2,9 b$ & $8,1 \mathrm{a}$ & $4,0 \mathrm{~b}$ & $6,9 a$ & 1,38 \\
\hline & & Catarina & $-{ }^{*}$ & $6,0 \mathrm{~ns}$ & $6,0 \mathrm{~ns}$ & $7,0 \mathrm{~ns}$ & 1,59 \\
\hline & \multirow{3}{*}{$\begin{array}{c}\text { Após } \\
\text { Armazenamento** }\end{array}$} & I. Gala & $6,0 b$ & $7,1 \mathrm{a}$ & $3,9 c$ & $7,5 a$ & 1,05 \\
\hline & & Fuji S & $4,5 b$ & $8,2 a$ & $7,0 \mathrm{a}$ & $7,8 a$ & 1,94 \\
\hline & & Catarina & - & $8,2 a$ & $6,4 \mathrm{~b}$ & $6,4 \mathrm{~b}$ & 1,32 \\
\hline \multirow{6}{*}{ Desidratação } & \multirow{3}{*}{$\mathrm{Na}$ Colheita } & I. Gala & Ons & Ons & Ons & Ons & 0,01 \\
\hline & & Fuji S. & Ons & Ons & Ons & Ons & 0,01 \\
\hline & & Catarina & - & Ons & Ons & Ons & 0,01 \\
\hline & \multirow{3}{*}{ Após Armazenamento } & I. Gala & $2,2 a b$ & $2,1 b$ & $3,1 \mathrm{a}$ & $1,7 b$ & 1,13 \\
\hline & & Fuji S. & $1,2 \mathrm{~ns}$ & $1,6 \mathrm{~ns}$ & $1,9 \mathrm{~ns}$ & $1,0 \mathrm{~ns}$ & 1,92 \\
\hline & & Catarina & - & $1,0 \mathrm{~ns}$ & $1,8 \mathrm{~ns}$ & $0,9 \mathrm{~ns}$ & 2,13 \\
\hline \multirow{6}{*}{ Aparência } & \multirow{3}{*}{ Na Colheita } & I. Gala & $7,2 b$ & $8,3 a$ & $3,5 c$ & $8,7 a$ & 0,78 \\
\hline & & Fuji S. & $3,6 c$ & $7,5 a$ & $3,1 \mathrm{c}$ & $5,8 b$ & 1,12 \\
\hline & & Catarina & - & $6,5 a b$ & $5,6 b$ & $6,8 a$ & 0,95 \\
\hline & \multirow{3}{*}{ Após Armazenamento } & I. Gala & $5,2 b$ & $6,8 a$ & $3,1 \mathrm{c}$ & $7,3 a$ & 1,41 \\
\hline & & Fuji S. & $5,0 b$ & $8,0 a$ & $4,9 b$ & $7,0 a$ & 1,81 \\
\hline & & Catarina & - & $6,3 a$ & $3,2 b$ & $3,3 b$ & 2,15 \\
\hline
\end{tabular}

Médias com letras distintas na linha diferem entre si pelo teste de Tukey $(P=0,05)$

ns- as médias não diferem significativamente; * $(-)$ traço significa não avaliado; DMS= diferença mínima significativa.

${ }^{* *}$ Períodos de armazenamento três meses de armazenagem para cvs. Gala e cinco meses para cvs. Fuji e Catarina, mais sete dias depois de retirada das frutas da câmara fria. 
MARTINS , C.R. et al. Qualidade sensorial de maçãs...

Um dos fatores fundamentais na qualidade de maçãs é a acidez, pois quando combinada com os açúcares, define o paladar. Além disso, acidez é um dos mais importantes parâmetros de qualidade de maçãs após a armazenagem, sendo considerada como a responsável pela baixa qualidade organoléptica das maçãs quando em baixo nível nas frutas (Tsuchiya, 2001; Lópes et al., 2002). A avaliação dos julgadores com relação à acidez no momento da colheita, não evidenciou diferenças nas frutas das três cultivares oriundas dos sistemas de produção estudados (Tabela 2). No entanto, quando as frutas foram avaliadas após o período de armazenamento, algumas diferenças foram observadas, nas cvs. Imperial Gala e Fuji Suprema. As maçãs produzidas em pomar conduzido em sistema orgânico demonstraram-se mais ácidas que as provenientes de sistema convencional (na faixa de acidez "ausente a levemente perceptível”). Os resultados obtidos na degustação indicam uma evolução diferenciada no consumo dos ácidos orgânicos durante o período de armazenamento. De acordo com Tsuchiya (2001) os principais problemas das maçãs conservadas por longos períodos são as perdas de suculência da resistência da polpa, e da redução da acidez, com aumento do açúcar resultando em perda da sensação refrescante causada pela baixa acidez. Segundo DeEll \& Prange (1992), que conduziram experimento semelhante, houve decréscimo acentuado na acidez das maçãs durante o armazenamento, mas não foi possível definir sensorialmente diferenças significativas entres as frutas oriundas de produção convencional e orgânica. O nível de nutrientes no solo mantém relação intrínseca com a acidez das frutas (Carvalho et al., 1994). Segundo autores como Carvalho et al. (1994) e Hunsche et al. (2003) verificaram que a deficiência do $\mathrm{K}$ no solo, além de afetar o tamanho e a firmeza interfere negativamente na acidez das maçãs comparativamente com as frutas oriundas de plantas bem nutridas. Segundo estes autores os ácidos orgânicos encontram-se dissolvidos nos vacúolos das células tanto na forma livre, como combinado, e quanto maior a concentração vacuolar de cátions, maior a concentração de ácidos orgânicos. Entretanto, estes ácidos não estão facilmente disponíveis à respiração da fruta.

TABELA 2 - Notas de acidez, aroma, sabor, maciez e suculência de maçãs, cvs. Imperial Gala, Fuji Suprema e Catarina, produzidas em pomares conduzidos em sistemas convencional (PC), integrado (PI), em transição convencional-orgânico (PET) e orgânicos (PO) na colheita e após armazenamento em atmosfera convencional, safra 2002/2003. São Joaquim, SC, 2004

\begin{tabular}{|c|c|c|c|c|c|c|c|}
\hline \multirow{2}{*}{ Características } & \multirow{2}{*}{ Períodos } & \multirow{2}{*}{ Cultivares } & \multicolumn{4}{|c|}{ Sistema de produção } & \multirow[b]{2}{*}{ DMS } \\
\hline & & & $\mathrm{PC}$ & $\mathrm{PI}$ & PET & $\mathrm{PO}$ & \\
\hline \multirow{6}{*}{ Acidez } & \multirow{3}{*}{ Na Colheita } & I. Gala & $4,3 \mathrm{~ns}$ & $3,4 \mathrm{~ns}$ & $5,1 \mathrm{~ns}$ & $4,9 \mathrm{~ns}$ & 0,68 \\
\hline & & Fuji S. & $2,1 \mathrm{~ns}$ & $3,9 \mathrm{~ns}$ & $2,6 n s$ & $4,2 \mathrm{~ns}$ & 2,45 \\
\hline & & Catarina & $--^{*}$ & $5,3 \mathrm{~ns}$ & $3,1 \mathrm{~ns}$ & $3,4 \mathrm{~ns}$ & 2,81 \\
\hline & \multirow{3}{*}{ Após Armazenamento** } & I. Gala & $1,5 \mathrm{c}$ & $2,8 b$ & $2,4 \mathrm{bc}$ & $3,9 a$ & 0,73 \\
\hline & & Fuji S. & $1,3 b$ & $3,3 a$ & $2,8 a b$ & $3,3 a$ & 0,71 \\
\hline & & Catarina & - & $3,0 \mathrm{~ns}$ & $1,9 \mathrm{~ns}$ & $2,8 \mathrm{~ns}$ & 1,96 \\
\hline \multirow{6}{*}{ Aroma } & \multirow{3}{*}{$\mathrm{Na}$ Colheita } & I. Gala & $5,4 \mathrm{~ns}$ & $5,6 \mathrm{~ns}$ & $3,9 \mathrm{~ns}$ & $3,4 \mathrm{~ns}$ & 2,21 \\
\hline & & Fuji S. & $4,1 \mathrm{~ns}$ & $3,8 \mathrm{~ns}$ & $4,3 \mathrm{~ns}$ & $4,2 \mathrm{~ns}$ & 1,21 \\
\hline & & Catarina & - & $3,7 \mathrm{~ns}$ & $4,0 \mathrm{~ns}$ & $4,2 \mathrm{~ns}$ & 1,44 \\
\hline & \multirow{3}{*}{ Após Armazenamento } & I. Gala & $4,4 \mathrm{~ns}$ & $4,4 \mathrm{~ns}$ & $4,4 \mathrm{~ns}$ & $4,1 \mathrm{~ns}$ & 0,79 \\
\hline & & Fuji S. & $6,3 \mathrm{~ns}$ & $6,6 \mathrm{~ns}$ & $4,9 \mathrm{~ns}$ & $4,9 \mathrm{~ns}$ & 1,14 \\
\hline & & Catarina & - & $5,2 \mathrm{~ns}$ & $4,6 \mathrm{~ns}$ & $4,4 \mathrm{~ns}$ & 0,89 \\
\hline \multirow{6}{*}{ Sabor } & \multirow{3}{*}{$\mathrm{Na}$ Colheita } & I. Gala & $6,3 \mathrm{~ns}$ & $7,1 \mathrm{~ns}$ & $7,8 \mathrm{~ns}$ & $7,2 \mathrm{~ns}$ & 1,79 \\
\hline & & Fuji S. & $5,3 \mathrm{~ns}$ & $5,2 \mathrm{~ns}$ & $5,6 \mathrm{~ns}$ & $5,7 \mathrm{~ns}$ & 1,03 \\
\hline & & Catarina & - & $4,8 \mathrm{~ns}$ & $5,7 \mathrm{~ns}$ & $5,6 \mathrm{~ns}$ & 0,99 \\
\hline & \multirow{3}{*}{ Após Armazenamento } & I. Gala & $4,1 \mathrm{~b}$ & $5,6 a$ & $4,0 b$ & $5,7 a$ & 1,11 \\
\hline & & Fuji S. & $6,6 \mathrm{~ns}$ & $7,5 \mathrm{~ns}$ & $6,8 \mathrm{~ns}$ & $5,8 \mathrm{~ns}$ & 1,87 \\
\hline & & Catarina & - & $7,2 a$ & $5,7 \mathrm{~b}$ & $6,6 a$ & 0,73 \\
\hline \multirow{6}{*}{ Maciez } & \multirow{3}{*}{$\mathrm{Na}$ Colheita } & I. Gala & $5,7 \mathrm{~ns}$ & $5,0 \mathrm{~ns}$ & $6,6 \mathrm{~ns}$ & $6,2 \mathrm{~ns}$ & 1,85 \\
\hline & & Fuji S. & $4,0 \mathrm{~ns}$ & $4,0 \mathrm{~ns}$ & $4,3 \mathrm{~ns}$ & $4,0 \mathrm{~ns}$ & 0,58 \\
\hline & & Catarina & - & $5,4 \mathrm{~ns}$ & $5,8 \mathrm{~ns}$ & $5,4 \mathrm{~ns}$ & 0,73 \\
\hline & \multirow{3}{*}{ Após Armazenamento } & I. Gala & $2,0 \mathrm{~b}$ & $3,7 a$ & $2,3 b$ & $4,5 a$ & 0,88 \\
\hline & & Fuji S. & $3,6 b$ & $5,6 a$ & $5,6 a$ & $5,3 a$ & 1,33 \\
\hline & & Catarina & - & $5,6 \mathrm{~ns}$ & $5,1 \mathrm{~ns}$ & $5,8 \mathrm{~ns}$ & 0,79 \\
\hline \multirow{6}{*}{ Suculência } & \multirow{3}{*}{ Na Colheita } & I. Gala & $6,2 \mathrm{~ns}$ & 7,0 ns & $6,0 \mathrm{~ns}$ & $6,5 \mathrm{~ns}$ & 0,87 \\
\hline & & Fuji S. & $6,3 \mathrm{~ns}$ & $7,0 \mathrm{~ns}$ & $6,4 \mathrm{~ns}$ & $6,7 \mathrm{~ns}$ & 1,19 \\
\hline & & Catarina & - & $5,8 \mathrm{~ns}$ & $5,9 \mathrm{~ns}$ & $6,1 \mathrm{~ns}$ & 1,05 \\
\hline & \multirow{3}{*}{ Após Armazenamento } & I. Gala & $3,8 b$ & $5,3 a$ & $3,9 b$ & $5,1 a$ & 1,19 \\
\hline & & Fuji S. & $6,1 \mathrm{~ns}$ & $7,0 \mathrm{~ns}$ & $6,1 \mathrm{~ns}$ & $6,7 \mathrm{~ns}$ & 0,97 \\
\hline & & Catarina & - & $6,6 \mathrm{~ns}$ & $5,3 \mathrm{~ns}$ & $5,4 \mathrm{~ns}$ & 1,86 \\
\hline
\end{tabular}

Médias com letras distintas na linha diferem entre si pelo teste de Tukey $(\mathrm{P}=0,05)$;

ns- as médias não diferem significativamente; *(-) traço significa não avaliado; DMS= diferença mínima significativa.

**Períodos de armazenamento três meses de armazenagem para cvs. Gala e cinco meses para cvs. Fuji e Catarina, mais sete dias depois de retirada das frutas da câmara fria. 
MARTINS , C.R. et al. Qualidade sensorial de maçãs...

$\mathrm{Na}$ atualidade, o aroma é um dos atributos de qualidade que está sendo cada vez mais pesquisado, já que é o resultado da composição de inúmeras sensações olfativas geradas por distintas moléculas de uma fruta (Saftner et al., 2002). Segundo estes autores, o aroma é um atributo de qualidade indiscutível, sendo que sua intensidade, além dos fatores pós-colheita como estádio de maturação e condições de armazenamento, parece manter relação intrínseca com fatores pré-colheita, como as condições de clima e de manejo da planta.

As características aromáticas das frutas foram igualmente avaliadas, tanto na colheita como após o armazenamento, sendo que, não houve constatação do efeito do sistema de produção (Tabela 2). Em estudo semelhante, pesquisadores não verificaram correlação entre os sistemas de produção de maçãs, convencional e orgânico, e aromas das maçãs cvs. Royal Gala e Fuji (Amarante et al., 2003).

De acordo com Chitarra (1994) o sabor das frutas se deve ao balanço entre os constituintes de doçura e acidez e, por vezes, de amargor ou adstringência. Nas avaliações de colheita, foi verificado que o sabor das frutas não foi afetado pelo sistema de produção. Porém, após o período de armazenamento, para as cultivares Imperial Gala e Catarina, houve influência desse fator sobre o sabor (Tabela 2). Nesse caso destacaram-se as frutas produzidas em sistemas orgânico e integrado. Segundo Azevedo (2003), os alimentos orgânicos são mais saborosos, por manterem os ácidos orgânicos, substâncias determinantes do sabor, cuja síntese é reduzida sob altas concentrações de fertilizantes nitrogenados prontamente solúveis. A complexidade envolvida nesse processo, desde a quantidade de fertilizantes solúveis até a quantidade de ácidos presentes nas frutas e as conseqüentes percepções pelo consumidor, dificultam a análise de fatores e/ou variáveis isoladas.

Os resultados encontrados na literatura são contraditórios. Borguini (2003) relatou que maçãs cv. Golden Delicious cultivadas em pomar orgânico apresentaram melhores características de sabor do que as produzidas em pomar convencional. Já DeEll \& Prang (1992) relataram que maçãs cvs. Cortland e Mclntosh cultivadas organicamente não apresentaram diferenças de sabor quando comparadas às produzidas em pomar convencional. Amarante et al. (2003) analisando o sabor das maçãs produzidas em sistemas convencional e orgânico, relataram que o sabor das maçãs cv. Gala, não foi influenciado pelo sistema de produção, mas na cv. Fuji houve influência, sendo as frutas produzidas em sistema orgânico, consideradas de melhor sabor.

$\mathrm{Na}$ avaliação sensorial a textura da polpa também foi avaliada pelo grau de maciez. Na colheita, as maçãs apresentaram textura semelhante entre os sistemas de produção, ou seja, o mesmo grau de maciez indicando polpa com textura "dura a tenra", nas três cultivares (Tabela 2). Após o armazenamento, a maior maciez da polpa foi observada, nas maçãs cv. Imperial Gala, naquelas provenientes de pomar conduzido em sistema convencional e em transição, consideradas frutas com textura "macia a mole". As frutas da cv. Imperial Gala dos demais sistemas apresentaram grau de maciez significativamente superior, de "tenro a macio", demonstrando melhor potencial de armazenamento, já que as frutas com maior crocância são preferidas pela maioria dos consumidores (Chitarra, 1994; Tsuchiya, 2001). As maçãs da cv. Fuji Suprema produzidas nos sistemas de produção convencional apresentaram após o armazenamento, grau de maciez significativamente inferior aos demais sistemas (Tabela 2). Na cv. Catarina não houve diferença significativa no grau de maciez após o armazenamento.

A suculência das frutas, nas três cultivares no momento da colheita, manteve-se na faixa de "regular a moderada" não sendo afetada pelos sistemas de produção (Tabela 2). Após o período de armazenamento, a suculência das frutas diminuiu na cv. Imperial Gala produzida em pomares conduzidos em sistema convencional e em transição. Essas frutas foram consideradas como "ligeiramente a regularmente suculentas", ao passo que, as maçãs produzidas em pomares conduzidos em sistema integrado e orgânico foram classificadas como "regular a moderadamente suculentas". As maçãs, cvs. Fuji Suprema e Catarina praticamente não alteraram a suculência em virtude do sistema de produção.

Conforme as avaliações realizadas na cv. Imperial Gala verificou-se a influência dos sistemas de produção na qualidade geral da fruta, sendo que, as provenientes dos sistemas integrado e orgânico foram classificadas como de qualidade superior (Tabela 3). A aparência e a coloração foram às variáveis que mais contribuíram na detecção das diferenças, principalmente nas frutas provenientes do sistema em transição, que possuíam menor tamanho e coloração. A qualidade geral das maçãs cv. Fuji Suprema não apresentaram diferenças significativas entre os sistemas de produção, tanto na colheita quanto após o armazenamento. Fato este que se repetiu à cv. Catarina no momento da colheita, mas após o armazenamento, as maças desta cultivar produzidas em sistema integrado apresentaram qualidade geral superior aos demais sistemas (Tabela 3). 
MARTINS , C.R. et al. Qualidade sensorial de maçãs...

TABELA 3 - Notas de qualidade geral e aceitação comercial de maçãs, cvs. Imperial Gala, Fuji Suprema e Catarina, produzidas em pomares conduzidos em sistemas convencional $(\mathrm{PC})$, integrado $(\mathrm{PI})$, em transição convencional-orgânico (PET) e orgânicos (PO) na colheita e após o armazenamento em atmosfera convencional, safra de 2002/2003. São Joaquim, SC, 2004.

\begin{tabular}{|c|c|c|c|c|c|c|c|}
\hline \multirow{2}{*}{ Características } & \multirow{2}{*}{ Períodos } & \multirow{2}{*}{ Cultivares } & \multicolumn{4}{|c|}{ Sistema de produção } & \multirow[b]{2}{*}{ DMS } \\
\hline & & & PC & $\overline{\mathrm{PI}}$ & PET & $\mathrm{PO}$ & \\
\hline \multirow{6}{*}{ Qualidade geral } & \multirow{3}{*}{ Na Colheita } & I. Gala & $6,0 b$ & $8,1 a$ & $5,5 b$ & $8,2 a$ & 1,30 \\
\hline & & Fuji S. & $4,1 \mathrm{~ns}$ & $5,9 \mathrm{~ns}$ & $4,8 \mathrm{~ns}$ & $5,4 \mathrm{~ns}$ & 1,97 \\
\hline & & Catarina & $--^{*}$ & $6,2 \mathrm{~ns}$ & $6,1 \mathrm{~ns}$ & $6,5 \mathrm{~ns}$ & 1,15 \\
\hline & \multirow{3}{*}{$\begin{array}{c}\text { Após } \\
\text { Armazenamento* }\end{array}$} & I. Gala & $4,7 b$ & $6,4 a$ & $4,3 b$ & $6,7 a$ & 1,60 \\
\hline & & Fuji S. & $5,7 \mathrm{~ns}$ & $7,7 \mathrm{~ns}$ & $5,6 \mathrm{~ns}$ & $6,4 \mathrm{~ns}$ & 1,39 \\
\hline & & Catarina & - & $7,5 a$ & $4,8 \mathrm{~b}$ & $5,2 \mathrm{~b}$ & 1,14 \\
\hline \multirow{6}{*}{$\begin{array}{l}\text { Aceitação } \\
\text { comercial }\end{array}$} & \multirow{3}{*}{ Na Colheita } & I. Gala & $7,6 a b$ & $7,6 a b$ & $5,7 \mathrm{~b}$ & $8,9 a$ & 1,59 \\
\hline & & Fuji S. & $5,1 \mathrm{~ns}$ & $6,8 \mathrm{~ns}$ & $5,4 \mathrm{~ns}$ & $6,5 \mathrm{~ns}$ & 1,75 \\
\hline & & Catarina & - & $7,3 \mathrm{~ns}$ & $7,3 \mathrm{~ns}$ & $7,3 \mathrm{~ns}$ & 0,65 \\
\hline & \multirow{3}{*}{$\begin{array}{c}\text { Após } \\
\text { Armazenamento }\end{array}$} & I. Gala & $5,3 b$ & $7,3 a$ & $4,7 \mathrm{~b}$ & $8,0 a$ & 1,15 \\
\hline & & Fuji S. & $5,1 \mathrm{~ns}$ & $7,1 \mathrm{~ns}$ & $5,4 \mathrm{~ns}$ & $6,1 \mathrm{~ns}$ & 2,51 \\
\hline & & Catarina & - & $7,1 a$ & $4,5 b$ & $4,1 \mathrm{~b}$ & 1,49 \\
\hline
\end{tabular}

Médias com letras distintas na linha diferem entre si pelo teste de Tukey $(P=0,05)$; ns- as médias não diferem significativamente; *(-) traço significa não avaliado; DMS= diferença mínima significativa.

**Períodos de armazenamento três meses de armazenagem para cvs. Gala e cinco meses para cvs. Fuji e Catarina, mais sete dias depois de retirada das frutas da câmara fria.

De maneira geral, a literatura relacionada à produção orgânica (Borguini, 2003; Darolt, 2001) apresenta resultados favoráveis a qualidade geral das frutas produzidas neste sistema, citando inclusive, que os atributos de maturação (firmeza da polpa, suculência, conteúdo de açúcar, aroma e sabor) são os de maior relevância na avaliação da qualidade geral e, favorecidos quando em sistema orgânico de produção. O modo como o alimento é produzido pode influenciar a composição nutricional e a qualidade organoléptica (Azevedo, 2003). No entanto, o efeito favorável ou não, frequentemente, depende das sensações particulares dos indivíduos em maior ou menor grau de aceitação (Lampkin, 1990).

Quando foi avaliada a qualidade geral das frutas da cv. Catarina observou-se que, no momento da colheita, as frutas obtidas nos pomares dos diferentes sistemas de produção apresentaramse com qualidade similar. Entretanto, após o armazenamento, as frutas provenientes do pomar em sistema integrado mantiveram-se com qualidade superior em relação aos sistemas em transição e orgânico. As frutas do sistema integrado foram classificadas como de qualidade "boa a ótima", enquanto que as frutas dos sistemas em transição e orgânico foram classificadas como de qualidade "regular". De acordo com os provadores, o principal fator que contribuiu para esta classificação foi a presença de frutas com sintomas de Bitter pit.

A aceitação comercial foi realizada pelos julgadores levando em consideração a possibilidade de comercialização e da própria aceitação da amostra pelos consumidores. Nesse atributo, as maçãs 'Imperial Gala', sob sistema orgânico, integrado e convencional, foram classificadas com maior escore de aceitação comercial em relação ao sistema em transição, no momento de colheita. Após o período de armazenamento a superioridade se resumiu apenas as frutas produzidas em sistema integrado e orgânico (Tabela 3). Quando se avaliaram as maçãs cv. Fuji Suprema pôde-se constatar uma aceitação similar entre os sistemas de produção, não havendo diferença significativa. Já com as maçãs cv. Catarina ocorreu uma variação na aceitação com a evolução do armazenamento, apresentando uma superioridade quando produzida em sistema integrado (Tabela 3 ).

$\mathrm{Na}$ avaliação conjunta das maçãs nos sistemas de produção pôde-se verificar, de um modo geral, uma superioridade nas características visuais das frutas produzidas em pomares conduzidos nos sistemas de produção integrado e orgânico em comparação com as frutas dos sistemas convencional e em transição. Nas características degustativas novamente verificou-se melhor desempenho, em geral, nas frutas produzidas em sistema integrado e orgânico, ressaltados pelos atributos de acidez, sabor, suculência e maciez.

Os resultados obtidos neste trabalho, não são suficientes para tomadas de posições definitivas em relação às frutas produzidas orgânicas e/ou em transição, no que concerne, à superioridade sensorial na conservação e na qualidade pós-colheita. Porém, o fato de serem produzidas sem o emprego de agrotóxicos e fertilizantes solúveis, produzindo frutas de boa 
MARTINS , C.R. et al. Qualidade sensorial de maçãs...

aparência, acidez, aroma, sabor e suculência, permite concluir que tem boas características comerciais, sugerindo a viabilidade do sistema.

\section{CONCLUSÃO}

De maneira geral, as frutas produzidas no sistema de produção integrado e orgânico apresentam qualidade sensorial superior às dos demais sistemas.

\section{REFERÊNCIAS}

1. ALTIERI, M. A.; ROSSET, P. Agroecology and the conversion of large-scale conventional systems to sustainable management. International Journal of Environmental Studies, v. 50, n. 3-4, p. 165-185, 1995.

2. AMARANTE, C. V. T. et al. Fisiologia de plantas e qualidade de fruto em pomares de macieira conduzidos nos sistemas orgânicos e convencional de produção. In: CONGRESSO BRASILEIRO DE AGROECOLOGIA, 1.; SEMINÁRIO INTERNACIONAL SOBRE AGROECOLOGIA, 4.; SEMINÁRIO ESTADUAL DE AGROECOLOGIA, 5. 2003, Porto Alegre. Anais... Porto Alegre: Emater, 2003. CD-ROM

3. AZEVEDO, E. Alimentos orgânicos - ampliando os conceitos de saúde humana, ambiental e social. Florianópolis: Insular, 2003. $200 \mathrm{p}$.

4. ASSOCIAÇÃO BRASILEIRA DE NORMAS TÉCNICAS (ABNT). NBR 12994: métodos de análise de sensorial de alimentos e bebidas. São Paulo, 1993.

5. BORGUINI, R. G. Tomate (Lycopersycum esculentum) orgânico: o conteúdo nutricional e a opinião do consumidor. 2003. 55 f. Dissertação (Mestrado em Ciência e Tecnologia de Alimentos) - Curso de pós-graduação em Ciência e Tecnologia de Alimentos, Escola Superior da agricultura Luiz de Queiroz, São Paulo, 2003.

6. BRASIL. Ministério da Agricultura e do Abastecimento. Instrução Normativa n. 07, de 17 de maio de 1999. Dispõe sobre normas para a produção de produtos orgânicos vegetais e animais. Diário Oficial [da] República Federativa do Brasil, Brasília, DF, p. 11, 19 maio 1999. Seção 1.

7. CARVALHO, J. G. et al. Influência dos nutrientes na qualidade de frutos. Informe Agropecuário, v. 17, n. 180, p. 52 55, 1994.

8. CAMILO, P. A.; DENARDI, F. Cultivares: descrição e comportamento no Sul do Brasil. In: EMPRESA DE PESQUISA AGROPECUÁRIA E EXTENSÃO RURAL DE SANTA CATARINA - EPAGRI (Ed.) A cultura da macieira. Florianópolis: Epagri, 2002. p. 113-166.

9. CERVEIRA, R.; CASTRO, M. C. Consumidores de produtos orgânicos da cidade de São Paulo - características de um padrão de consumo. Ecossistema, v. 25, n. 2, p.199-206, 2000.

10. CHITARRA, M. I. F. Colheita e qualidade pós-colheita de frutos. Informe Agropecuário, v. 17, n. 179, p. 8-18, 1994.

11. CZELUSNIAK, C. et al. Qualidade de maçãs comerciais produzidas no Brasil: aspectos físicos-quimicos. Brazilian Journal of Food Technology, v. 6, n. 1, p. 25-31, 2003.

12. DAROLT, M. R. A qualidade nutricional do alimento orgânico é superior ao convencional? Disponível em: < http://redeagroecologia.cnptia.embrapa.br/biblioteca/impactos-da-agricultura-convencional/conv\%20X\%20org.pdf/>. Acesso em: 11 nov. 2001.

13. DeEII, J. R.; PRANGE, R. K. Postharvest quality and sensory attributes of organically and conventionally grown apples. Hortscience, v. 27, n. 10, p. 1096-1099, 1992.

14. LÓPES, M. L. et al. Maduración y conservación de manzanas fuji. Fruticultura Profesional, n. 128, p.110-116. 2002.

15. EMPRESA DE PESQUISA AGROPECUÁRIA E EXTENSÃO RURAL DE SANTA CATARINA (EPAGRI). Diagnostico do meio rural: levantamento sistemático da produção agropecuária. São Joaquim: Escritório local da Epagri São Joaquim, 1999. $73 \mathrm{p}$.

16. FERGUNSON, I.; VOLZ, R. WOOLF, A. Preharvest factors affecting physiology disorders of fruit. Postharvest Biology and Technology, v. 15, n. 3, p. 255-262. 1999.

17. GIRARDI, C. L.; SANHUEZA, R. M. V.; BENDER, R. J. Manejo pós-colheita e rastreabilidade na produção integrada de maçãs. Bento Gonçalves: Embrapa Uva e Vinho, 2002. 23 p. (Circular Técnica, 31).

18. HUNSCHE, M.; BRACKMANN, A.; ERNANI, P. R. Efeito da adubação potássica na qualidade pós-colheita de maçãs Fuji. Pesquisa Agropecuária Brasileira, v. 38, n. 4, p. 489-496, 2003.

19. HUTCHINS, R. K.; GREENHALGH, L. A. Organic confusion: sustaining competitive advantage. British Food Journal, v. 99 , n. 9, p. 336-338, 1997.

20. LAMPKIN, N. The wider issues. In: LAMPKIN, N. Organic farming. 2. ed. Ipswich: Press Books, 1990. cap.15, p. 557-616.

21. ORMOND, J. G. P. et al. Agricultura orgânica: quando o passado é futuro. BNDES Setorial, n. 15, p. 3-34, 2002.

22. RIBEIRO, G. M. et al. Qualidade de frutos em macieira conduzidos nos sistemas orgânico e convencional de produção. In: CONGRESSO BRASILEIRO DE FRUTICULTURA, 17., 2002, Belém. Anais... Belém: Sociedade Brasileira de Fruticultura, 2002. p.142.

23. SAFTNER, R. A. et al. Instrumental and sensory quality characteristics of Gala apples in response to prestorage heat, controlled atmosphere, and air storage. Journal American Society Horticultural Science, v. 127, n. 6, p.1006-1012, 2002.

24. SILVA, J. G. da. Tecnologia e agricultura familiar. Porto Alegre: UFRGS, 1999. $238 \mathrm{p}$

25. SOUZA, M. C. M. Aspectos institucionais do sistema agroindustrial de produtos orgânicos. Informações Econômicas, v. 33, n. 3, p. 7-16, 2003.

26. SUSLOW, I. Postharvest handling for organic crops. Disponível em: < http://ucanr.org/freepubs/docs/7254.pdf> Acesso em: 21 mar. 2002.

27. TSUCHIYA, S. Perspectivas das novas cultivares japonesas de maçã no Brasil. In: ENFRUTE ENCONTRO NACIONAL SOBRE FRUTICULTURA DE CLIMA TEMPERADO, 4., 2001, Fraiburgo. Anais... Caçador: Epagri, 2001. p. $58-68$

Recebido em: 13/02/2009 Aceito em: 24/11/2009 
